[Supporting Information]

\title{
Mechanism of LDH Direct Growth on Aluminium Alloy Surface: A Kinetic and Morphological Approach
}

A.C. Bouali ${ }^{1 *}$, M.H. Iuzviuk ${ }^{2}$, M. Serdechnova ${ }^{1}$, K.A. Yasakau ${ }^{3}$, D. Drozdenko ${ }^{4}$, A. Lutz ${ }^{5}$, K. Fekete $^{4}$, G. Dovzhenko ${ }^{6}$, D.C.F. Wieland ${ }^{7}$, H. Terryn ${ }^{5}$, M.G.S. Ferreira ${ }^{3}$, I.A. Zobkalo ${ }^{2}$, M.L. Zheludkevich ${ }^{1,8}$.

${ }^{1}$ Institute of Surface Science, Helmholtz-Zentrum Hereon, Max-Planck-Straße 1, 21502 Geesthacht, Germany.

${ }^{2}$ Petersburg Nuclear Physics Institute named by B.P. Konstantinov of National Research Centre «Kurchatov Institute», Laboratory of Physics of Crystals, Leningradskaya Oblast, 1, mkr. Orlova Roshcha, 188300 Gatchina, Russia

${ }^{3}$ CICECO - Aveiro institute of materials, Dep. Materials and Ceramic Engineering, University of Aveiro, 3810-193 Aveiro, Portugal.

${ }^{4}$ Faculty of Mathematics and Physics, Department of Physics of Materials, Charles University, Ke Karlovu 5, 12116 Prague 2, Czech Republic.

${ }^{5}$ Research Group Electrochemical and Surface Engineering, Vrije Universiteit Brussel, Pleinlaan 2, Etterbeek, 1050 Brussels, Belgium.

${ }^{6}$ Institute of Materials Physics, Helmholtz-Zentrum Hereon, Max-Planck-Straße 1, 21502 Geesthacht, Germany.

${ }^{7}$ Institute of Metallic Biomaterials, Helmholtz-Zentrum Hereon, Max Planck Straße 1, 21502 Geesthacht, Germany.

${ }^{8}$ Faculty of Engineering, Kiel University, Kaiserstraße 2, 24143 Kiel, Germany.

* Corresponding author: A.C. Bouali, email: anissa.bouali@hereon.de 
a)

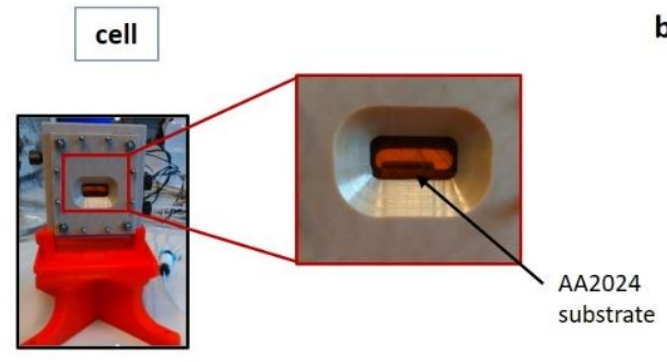

b)
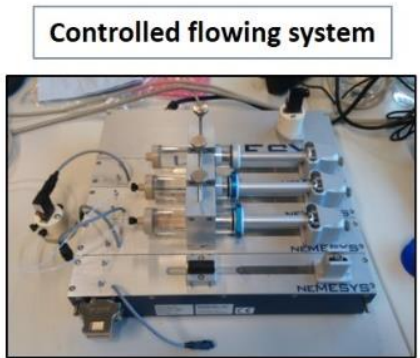

c)

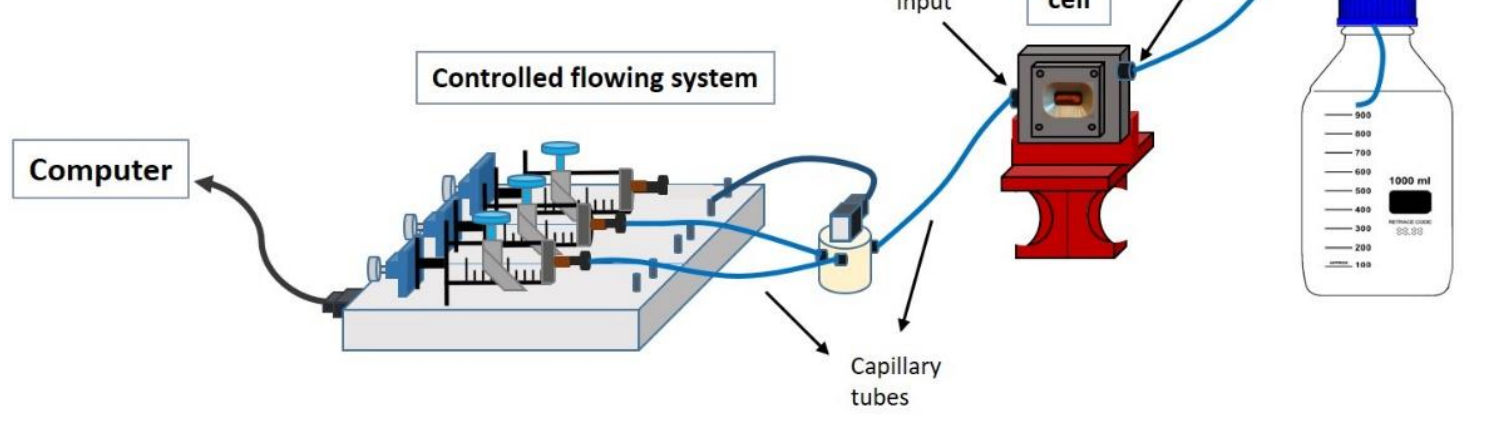

Figure S1. Photographs of the synthesis cell a), the controlled flowing system b) and a scheme of the general set-up used for the synthesis monitoring during synchrotron measurements $\mathbf{c}$ ).

Adapted with permission from (49) Bouali, A.C.; Iuzviuk, M.H.; Serdechnova, M.; Yasakau, K.A.;

Wieland, D.C.F.; Dovzhenko, G.; Maltananva, H.; Zobkalo, I.A.; Ferreira, M.G.S.;

Zheludkevich, M.L. Zn-Al LDH Growth on AA2024 and Zinc and their Intercalation with Chloride: Comparison of Crystal Structure and Kinetics. Appl. Surf. Sci. 2020, 501, 14402714036. Copyright 2019 Elsevier. 


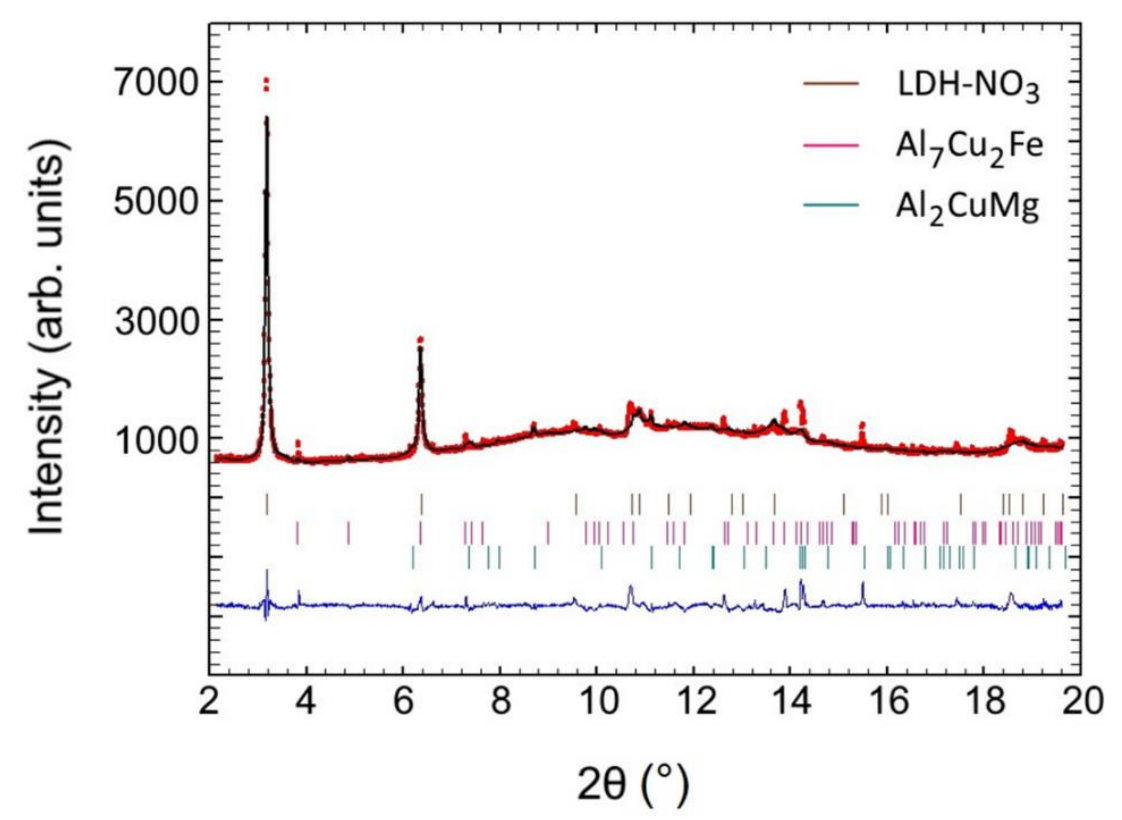

Figure S2. XRD pattern along with the Rietveld refined data for the AA2024 sample after ZnAl $\mathrm{LDH}-\mathrm{NO}_{3}$ formation. Peaks corresponding to $\mathrm{Al}$ element have been eliminated. The red line is the experimental data, the black line is the calculated one and the blue line is the difference profile. The peaks corresponding to LDH and secondary phases are marked by small vertical lines in different colours ( $\mathrm{LDH}$ marks are in brown, $\mathrm{Al}_{7} \mathrm{Cu}_{2} \mathrm{Fe}$ in pink, and $\mathrm{Al}_{2} \mathrm{CuMg}$ in green).

Table S1. XRD reflections associated with the LDH phases and the IMCs in AA2024.

\begin{tabular}{|c|c|c|c|c|c|}
\hline \multicolumn{2}{|c|}{$\mathbf{L D H}$} & \multicolumn{2}{c|}{$\mathbf{A l}_{\mathbf{7}} \mathbf{C u}_{2} \mathbf{F e}$} & \multicolumn{2}{c|}{$\mathbf{A l}_{\mathbf{2}} \mathbf{C u M g}$} \\
\hline $\mathbf{2 \theta}(\mathbf{o b s}) \boldsymbol{\circ}^{\circ}$ & $\boldsymbol{h} \boldsymbol{k} \boldsymbol{l}$ & $\mathbf{2 \theta}(\mathbf{o b s}){ }^{\circ}$ & $\boldsymbol{h} \boldsymbol{k} \boldsymbol{~}$ & $\mathbf{2 \theta}(\mathbf{o b s}) \boldsymbol{\circ}^{\circ}$ & $\boldsymbol{h} \boldsymbol{k} \boldsymbol{l}$ \\
\hline 3.19 & 003 & 3.82 & 002 & 6.19 & 020 \\
\hline 6.38 & 006 & 6.35 & 110 & 11.13 & 112 \\
\hline 9.58 & 009 & 7.41 & 112 & 14.23 & 200 \\
\hline 10.72 & 101 & 8.98 & 200 & 14.28 & 113 \\
\hline 10.88 & 012 & 10.05 & 210 & & \\
\hline 11.49 & 104 & 10.75 & 212 & & \\
\hline 13.66 & 018 & 11.46 & 006 & & \\
\hline 18.53 & 110 & 11.57 & 213 & & \\
\hline 18.81 & 113 & 12.63 & 214 & & \\
\hline 19.23 & 0018 & 13.63 & 301 & & \\
\hline & & 14.67 & 303 & & \\
\hline & & 17.77 & 208 & & \\
\hline
\end{tabular}




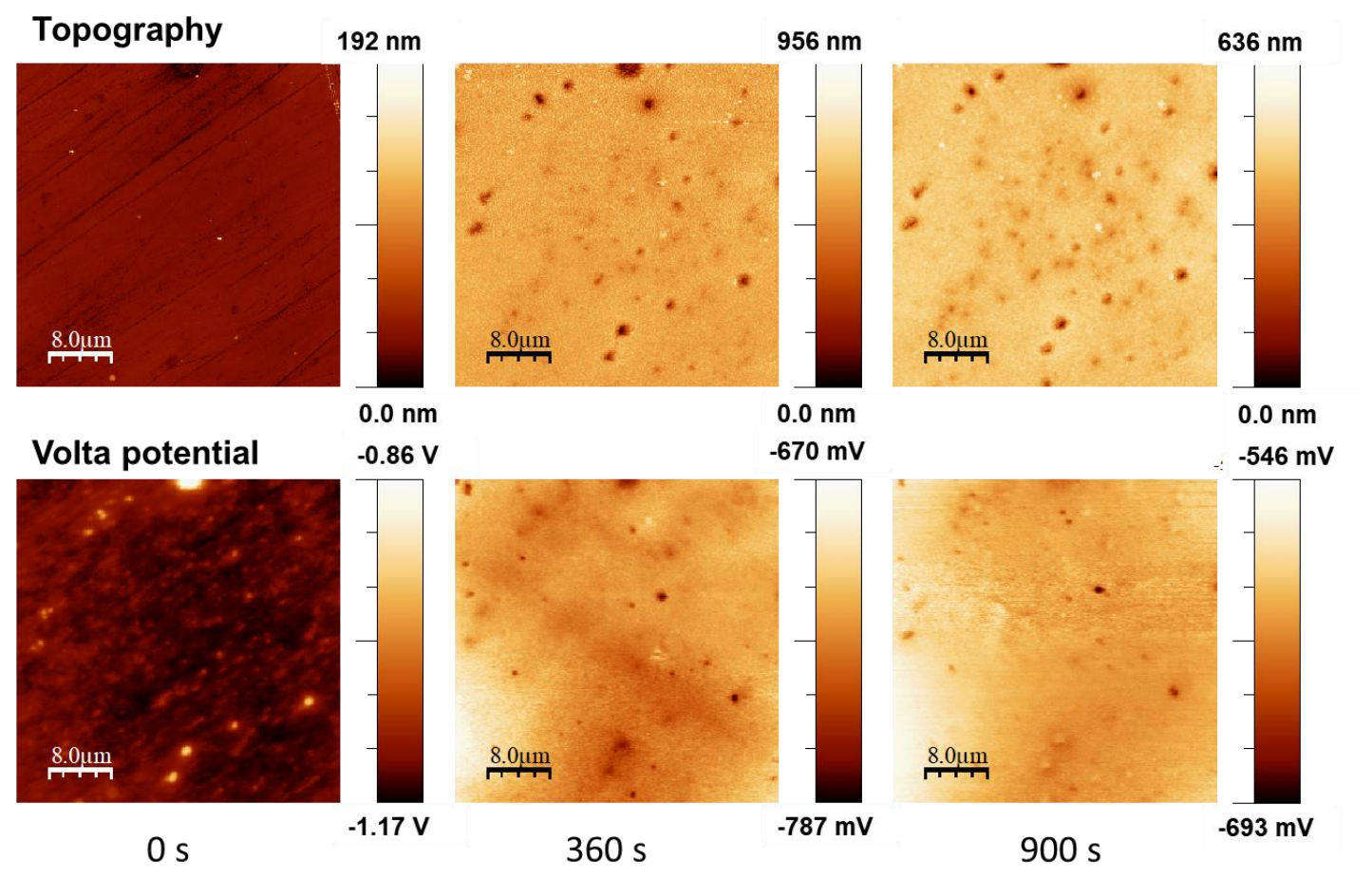

Figure S3. Topography (Top) and VPD (Bottom) changes of the AA2024 surface before and after different immersion times in DI water at $95^{\circ} \mathrm{C}$.

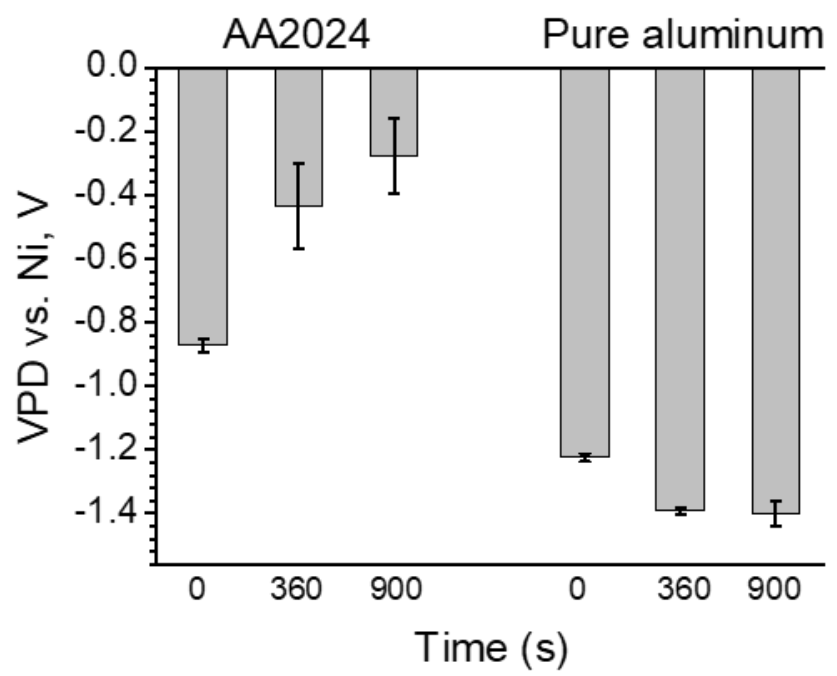

Figure S4. VPD changes on AA2024 and pure Al surfaces before and after different immersion times in DI water at $95^{\circ} \mathrm{C}$. 


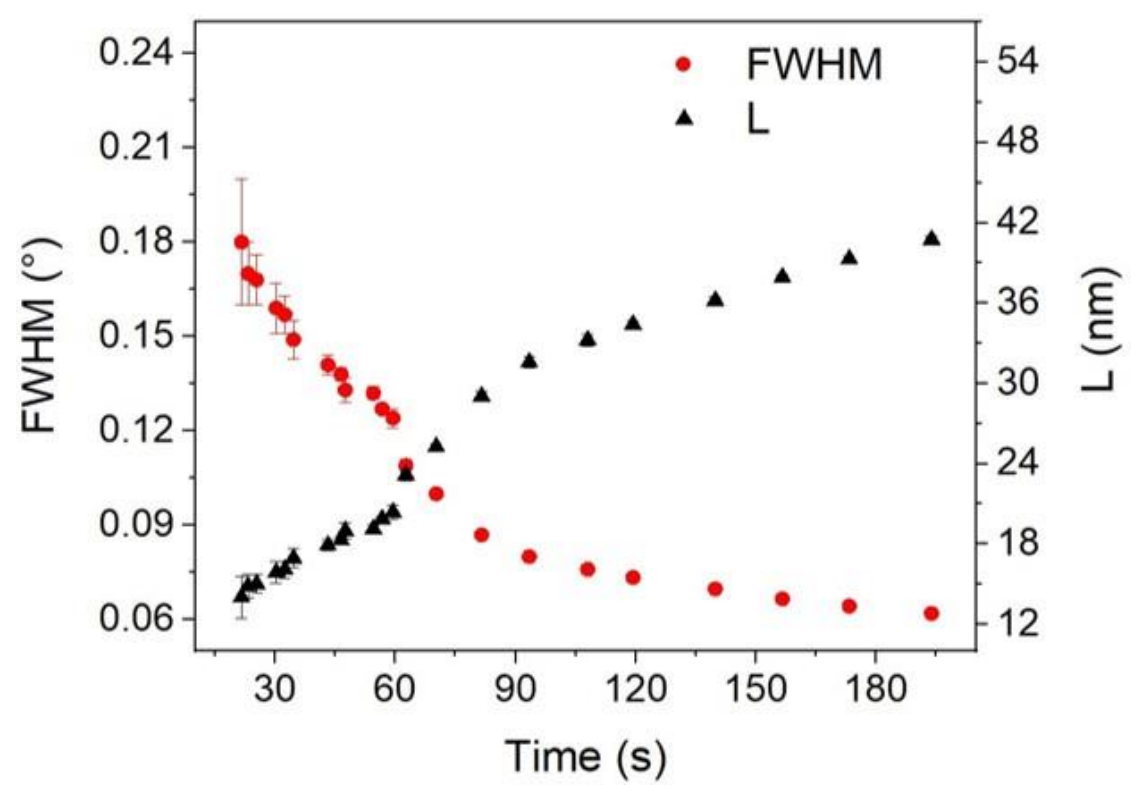

Figure S5. Graphs representing the time dependences of FWHM and flake size "L". The values were extracted from the (003) reflection. 